\title{
An Exploration of State Legislator Communication Technology Use and
}

\section{Importance}

\author{
Joe F. West* \\ Assistant Professor, Department of Political Science and Public Administration \\ University of North Carolina at Pembroke \\ 1 University Drive \\ Pembroke, NC 28372 \\ (V) $910-521-4410$ \\ Email: Joe.West@uncp.edu \\ Elizabeth A. Corley \\ Professor, School of Public Affairs \\ Arizona State University \\ 411 N. Central Avenue, Suite 450 \\ Phoenix, AZ 85004-0687 \\ (V) 602-496-0462 \\ Email: Elizabeth.corley@asu.edu
}

Submitted to the Journal of Information Technology and Politics

December 2015

* Corresponding author 


\title{
An Exploration of State Legislator Communication Technology Use and Importance
}

\begin{abstract}
This article explores the importance and communication frequency associated with legislator use of communication technologies (CTs). Demographic variations are examined. Our results suggest that significant complexity surrounds legislator utilization of CTs for their interactions with peers and constituents. For example, we conclude that: 1) legislators find mature CTs more important than Internet enabled CTs, 2) legislator age and years in office impact the use of CTs, with older and younger legislators communicating less frequently, 3) gender is not a significant differentiator in CT use or importance, and 4) minority party legislators communicate more frequently than their majority party counterparts.
\end{abstract}

Keywords: Legislator Behavior, Communication Technology Frequency of Use, Communication Technology Importance, ICT. 


\section{An Exploration of How State Legislators Use Communication Technologies Introduction}

Robert Dahl (1989) intuitively forecast that communication technology (CT) would change the face of democracy. In line with this prediction, relatively recent developments in CT (such as social media websites Facebook ${ }^{\mathrm{TM}}$ and Twitter $^{\mathrm{TM}}$ ) are facilitating new and diverse linkages between legislators and constituents. As a result, scholars are beginning to predict that these linkages may be changing the landscape of democracy in unanticipated and unpredictable ways.

In this article, we explore how the development of new communication technologies is related to the way legislators interact with their constituents and peers. To capture these changes empirically, we use data from a 2013 survey with Arizona State Legislators. Specifically, we use the survey data to examine the frequency of use and importance that legislators attach to the most widely used CTs. In addition, we use these data to explore how CT frequency of use and importance vary as a function of demographic and political variables. In our study, we focus on eight of the most commonly used CTs by the Arizona State Legislature. These technologies include mature technologies like face-to-face communications ${ }^{1}$, phone calls, and letters, as well as more recent technologies like E-mail, webpages, blogs, and social media sites (e.g., Facebook ${ }^{\mathrm{TM}}$ and Twitter ${ }^{\mathrm{TM}}$ ).

We developed the hypotheses for our study using the results of existing studies that focus on the demographic relationships surrounding the use of CT for both non-legislators and legislators. Even though the majority of this literature focuses on non-legislators, there are a few examples of literature that focuses on legislator use of CT. These studies suggest that legislator behavior is impacted by the CTs they use. Given that a substantial amount of 
work has been done in this area already, we believe that the most unique research question at this time is not whether there is a significant relationship between legislator behavior and CT, but rather how the use of different CTs is related to legislator behavior. This article focuses on this latter question.

The analysis in this article departs from (and adds to) the existing literature in multiple ways. First, we examine the frequency of use and the perceived importance of a wide range of CTs rather than focusing on a single CT. This approach is relatively underutilized in the literature because it examines both mature CTs (such as face-to-face meetings) as well as Internet Enabled CTs (IECTs) ${ }^{2}$ such as E-Mail, Facebook ${ }^{\mathrm{TM}}$ and Twitter $^{\mathrm{TM}}$. Second, we differentiate between the frequency of use of a CT and the legislator assigned importance of that technology, two concepts that while related, can be easily conflated. Because we have identified no existing studies that examine CT frequency of use over a broad range of CTs, nor any studies that examine the importance that legislators assign to various CTs, we believe this study bridges an important knowledge gap.

We address three specific goals in this article. First, we use our study results to contribute to the literature on the relationship between demographic variables and CT use by examining legislators rather than only non-legislators (which is the focus of the majority of the existing literature). Second, we explore the relationship between peer CT use/importance and constituent CT use/importance. Lastly, we examine the importance that legislators assign to various CTs. To create testable hypotheses from these goals, we have generated two research questions.

Research Question 1: Which CTs do Arizona State Legislators use to communicate with their constituents and peers? How frequently do they use these CTs? What importance do they place on them? 
Research Question 2: To what extent are the demographic characteristics of state legislators correlated with CT frequency of use and importance? What relationships exist between CT frequency of use and importance?

In the next section, we will discuss the existing literature that is related to our research questions. We will also explain how we used this literature to develop our hypotheses for the article.

\section{Variables Impacting Communication Technology Frequency Of Use}

To comprehensively analyze the existing literature in this area, we first categorized the variables that impact legislator frequency of use for any particular CT into two groups: individual characteristics of the legislator and variables external to the legislator. According to the existing literature, the individual characteristics that might impact CT frequency of use include demographic variables such as age (Carpenter \& Buday, 2007; Juznic, Blazic, Mercun, Plestenjak, \& Majcenovic, 2006; A. Morris, Goodman, \& Brading, 2007; Peacock \& Künemund, 2007), gender (Akman \& Mishra, 2010; Hogan, 2006; M. G. Morris, Venkatesh, \& Ackerman, 2005; Thayer \& Ray, 2006), education (Chen \& Persson, 2002; Cutler, Hendricks, \& Guyer, 2003; Selwyn, Gorard, Furlong, \& Madden, 2003; Tak \& Hong, 2005), and political party affiliation (Greenberg, 2012). Also included in this category are more nuanced variables such as attitudes toward aging (Cody, Dunn, Hoppin, \& Wendt, 1999), computer anxiety and self-efficacy (Cody et al., 1999), interest in computers (L, Morrell, Park, Christopher, \& Mayhorn, 1999), health (Carpenter \& Buday, 2007; Chen \& Persson, 2002; Selwyn et al., 2003), and personality (Chen \& Persson, 2002).

On the other hand, most of the external variables are associated with technology accessibility (Mergel, 2012; Peterson, 2012; Pratt et al., 2012) and the impact of institutional (elected chamber) effects. Since legislators in this study share a common 
Information Technology (IT) infrastructure, external variables such as access to the Internet, Internet connection speed, access to E-Mail, and availability of a computer can be normalized and cease to be a source of frequency of use and importance variations. In essence, there is no "digital divide" influencing frequency of use or importance when legislators share a common IT infrastructure.

In developing hypotheses, we assume that state legislator CT use is impacted by similar internal variables that impact federal legislators and non-legislators. For instance, age is a significant indicator of CT use among non-legislators and therefore we expect it to be a significant indicator of CT use for legislators as well. The following sections examine some of the literature surrounding variables that may impact how frequently legislators use CTs, beginning with one of the most influential factors: age.

\section{Age}

The impact of age on the use of CTs is well documented with researchers typically finding that age is negatively correlated with the use of CT. Not surprisingly, the older an individual is, the less likely they are to use a computer (Carpenter \& Buday, 2007; Cutler et al., 2003; Friedberg, 2001). Even if older individuals own a computer, they are also less likely to use the Internet to communicate (Madden \& Savage, 2000; A. Morris et al., 2007; Selwyn et al., 2003). In one example of the impact of age, Greenberg's (2012) investigation into the use of social media by U.S. Congress members found that, on average, older legislators use social media less than younger legislators. Greenberg found that this age trend held true across both Facebook ${ }^{\mathrm{TM}}$ and Twitter $^{\mathrm{TM}}$, but the effect of age was strongest with Facebook ${ }^{\mathrm{TM}}$. In a second example of the relationship between legislator age and the use of a CT, Sala \& Jones (2012) found an inverse relationship between age and social 
media use (Facebook ${ }^{\mathrm{TM}}$ and Twitter ${ }^{\mathrm{TM}}$ ) among Texas legislators, yet found no such relationship among Mexican legislators. Their results suggest that the inverse relationship between legislator age and the use of social media is not universal and may not span cultural boundaries.

Cooper (2004) found a statistically significant (95\% CI) negative relationship between legislator age and Internet use that can be interpreted as a one year increase in age resulting in a 5.2\% decrease in the likelihood that a legislator will use the Internet for policy research. Cooper's findings are consistent with research into legislator behavior by Pole (2000), who found that older legislators are slow to embrace IT, as well as Conte (1999) who found that older legislators struggle with IT. Conte's results are confirmed by West (2014) who found through interviews with Arizona State Legislature IT staff, that older legislators comprised the bulk of IT support work because of their unfamiliarity with, and difficulty using, Internet enabled CTs. Based on the literature, we expect that age will play a role in CT frequency of use and importance, leading to the first three hypotheses: $H_{1 a:}$ An increase in legislator age is correlated with a decrease in Internet Enabled Communication Technology (IECT) use.

$H_{1 b:}$ An increase in legislator age is correlated with an increase in mature communication technology use.

H1c: An increase in legislator age is correlated with a decrease in social media use.

\section{Gender}

Research focused on the relationship between gender and frequency of use for CTs is somewhat less prolific than research on age; yet the relationship is widely documented. Research involving participants who did not share a common CT infrastructure generally 
reported gender as a significant differentiator in computer usage (Hogan, 2006; Li \& Kirkup, 2007; Selwyn et al., 2003; Thayer \& Ray, 2006) and Internet access (Fang \& Yen, 2006; Hills \& Argyle, 2003; Li \& Kirkup, 2007). A short survey of the findings in the above research include results that suggest: women are less likely to embrace new technologies than men (Hogan, 2006), men are more likely to use the Internet, E-Mail, and online chat rooms than women, (Li \& Kirkup, 2007) men are more likely to use a computer than women (Selwyn et al., 2003) and women are more likely to use E-Mail to communicate with friends and relatives than are men (Thayer \& Ray, 2006).

The above studies examined gender differences between men and women who did not share a common CT infrastructure. The literature demonstrates that when men and women share a CT infrastructure, the results are different. Akman and colleagues (2010), Knight (2005), and Thayer (2006) examined participants who shared common CT infrastructure (as company employees, knowledge workers across companies, and university students across universities respectively). These studies found no statistically significant relationship between gender and Internet use. The above research suggests that CT infrastructure access may be correlated with differences in CT use as a function of gender.

Since the legislators in our study share a common IT infrastructure, we do not expect gender to play a statistically significant role in CT frequency of use, although it may play a role in CT importance. This leads to our second hypothesis:

$H_{2 a}:$ Legislator gender is not correlated with Internet enabled communication technology use.

$H_{2 b}$ : Legislator gender is not correlated with mature communication technology use. 


\section{Education}

Researchers generally find that increases in education are correlated with an increase in computer and Internet use (Chen \& Persson, 2002; Juznic et al., 2006; Tak \& Hong, 2005), both of which play a role in CT use. There is also a relationship between education and income that impacts CT use, with studies noting that computer and Internet users have both more education and higher incomes than non-users (Graham, 2002; Warschauer, 2004). In an example of research that is similar to ours, Williams and Gulati (2009) found education to be correlated to legislator use of Facebook ${ }^{\mathrm{TM}}$ during campaigning. We expect that education will impact CT frequency of use, leading to our third hypothesis. $H_{3 a:}$ An increase in legislator education level is correlated with an increase in Internet Enabled Communication Technology (IECT) use.

$H_{3 b:}$ An increase in legislator education level is correlated with an increase in mature
communication technology use.

\section{Political Party}

Several researchers who have investigated Twitter ${ }^{\mathrm{TM}}$ use in the $111^{\text {th }}$ U.S. Congress found that Republicans use Twitter ${ }^{\top M}$ (Greenberg, 2012; Lassen \& Brown, 2011; Peterson, 2012; Straus, Glassman, Shogan, \& Smelcer, 2013) and Facebook ${ }^{\mathrm{TM}}$ (Greenberg, 2012) more frequently than their Democrat counterparts. Significantly, Straus et al. (2013) hypothesized that the minority party, in an attempt to represent a broader constituency, will use Twitter ${ }^{\mathrm{TM}}$ more frequently. Expanding Straus et al.'s minority party Twitter ${ }^{\mathrm{TM}}$ hypothesis to all CTs would suggest that Democrats (the minority party in the Arizona legislature) would use all CTs more frequently than Republicans. The broader constituency theory proposed by Straus et al. is common in the literature, not necessarily in name, but in concept with a number of authors supporting the theory that the minority party spends 
time communicating with constituents for the express purpose of increasing voter turnout in greater numbers than the majority party (for example, see (Green \& Gerber, 2004; Inouye, 2014; Messmer, 2001)). It seems reasonable to expect that members of the minority party would use their time to grow a support base in an effort to become the majority party.

In addition to the broader constituency theory outlined previously, there are other party status influences that may result in CT frequency of use differences between the majority and minority parties. These include the following: The minority party has more time available to communicate than the majority party because they are less involved in the legislative process (Messmer, 2001; Oleszek, 2011; West, 2014), the minority party uses CT to promote their message due to a lack of attention by the media who is more focused on the actions of the majority party (Cook, 1989; Cooper, 2002; Kedrowski, 1992; Lassen \& Brown, 2011; Lathrop \& Ruma, 2010; Messmer, 2001), and the minority party uses social media to shine light on the actions of the majority party (Lathrop \& Ruma, 2010).

Based on the previous paragraphs, we can develop our fourth hypothesis: $H_{4 a:}$ Legislators in the minority party will use Internet Enabled Communication
Technology (IECT) more frequently than their majority party counterparts.

$H_{4 b:}$ Legislators in the minority party will use mature communication technologies more frequently than their majority party counterparts.

\section{Institution (Chamber)}

We were not able to locate many studies that examine the influences of elected chamber on CT frequency of use directly, but we did find two studies that note variations in CT frequency of use as a function of elected chamber. Greenberg's (2012) research into congressional use of social media produced evidence that House members engaged in 
fewer posts per day to Facebook ${ }^{\mathrm{TM}}$ and fewer tweets to Twitter ${ }^{\mathrm{TM}}$ than their Senate colleagues. Alperin (2003) who investigated E-Mail use for Wisconsin and Minnesota state legislators, found that the per-capita E-mail communications by House members were approximately double that of their counterparts in the Senate for both state legislatures. Based on the above research, we developed hypotheses $\mathrm{H}_{5}$ and $\mathrm{H}_{5 b}$.

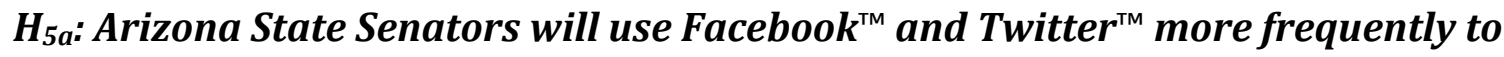
communicate with constituents than Arizona State Representatives.

$H_{5 b:}$ Arizona State Representatives will use E-Mail more frequently to communicate with constituents than Arizona State Senators.

\section{Variables Impacting Communication Technology Importance}

Within the literature, we found no empirical research on the relative importance legislators assign to a wide range of CTs. Because of the dearth of research in this area, we offer no hypotheses related to CT importance. Instead, we conduct an exploratory analysis in this area. Hopefully, our results for this portion of our study will lead to more detailed hypothesis testing in future projects.

\section{Data Collection and Methodology}

\section{Research Population}

For our study, we chose The Arizona State Legislature as the research population. The Arizona State Legislature is a bicameral body composed of the House of Representatives (House) and Senate. The Arizona House (the lower body) is comprised of 60 members, two members from each of Arizona's 30 legislative districts, and the Senate (the upper body) is comprised of 30 members, one member from each legislative district. Based on a review of legislator names and photographs published on the Arizona House 
and Senate member pages, there are 12 women and 18 men in the Senate and 19 women and 41 men in the House.

\section{Survey Modes}

The survey data collection for this study consisted of Internet and mail survey delivery modes, modeled after the Tailored Design Method approach developed by Dillman and colleagues (Dillman, Smyth, \& Christian, 2009). The Internet mode survey data collection began on March 20, 2013, when the official invitation to participate in the online survey was E-mailed to legislators. The email invitation contained a link to the Qualtrics online survey. Follow-up (reminder) emails were sent on March 27, 2013 and April 5, 2013. The second survey mode, a USPS mailing, was initiated on April 25, 2013. On this date, we sent letters containing a personalized introduction with instructions, a printed copy of the online survey, a stamped, self-addressed envelope to all legislators. The first mail mode responses from legislators were received on May 2, 2013 and were received intermittently through June 5, 2013. The survey was closed on June 5, 2013.

\section{Instrument}

The survey instrument consisted of an introductory cover letter briefly outlining the study and obtaining participant consent followed by eleven questions. These questions consisted of six demographic questions focused on the following variables: legislator age, gender, level of education, legislator chamber, political party, and years in office. In addition, there were four questions that were used to develop some of our dependent variables. Specifically, there were two questions focused on the frequency of use and importance of CTs used to communicate with other legislators, and two questions focused on the frequency of use and importance of CTs used to communicate with constituents. 
These questions about CT frequency of use and importance were asked multiple times across specific CT or hardware technologies. In particular, we asked these questions about eight forms of CTs: 1) face-to-face meetings, 2) telephone calls, 3) letters (hardcopy), 4) Email, 5) Twitter ${ }^{\mathrm{TM}}$, 6) Facebook ${ }^{\mathrm{TM}}$, 7) webpages, and 8) blogs.

In the questionnaire, the communication frequency of use variables were ordinal in nature, with the following response categories: do not use (coded as 0), use annually (coded as 1), use monthly (coded as 2), use weekly (coded as 3), use daily (coded as 4), and use hourly (coded as 5). The CT importance of use variables were also ordinal in nature with the following response categories: do not use (coded as 0 ), not important (coded as 1 ), slightly important (coded as 2), moderately important (coded as 3), important (coded as 4), and very important (coded as 5).

The fifth and final dependent variable, legislator use of technology hardware, was developed from a question that asked legislators how often they used the following hardware devices: desktop computer, laptop computer, net-book or small laptop, tablet device, smart phone, basic cell phone, smart-watch, pocket digital media player, and other. Response categories for this variable were the same as the communication frequency variable.

\section{Results}

\section{Legislator Survey Response Demographics}

The average age for the population of Arizona Senators and Representatives on January $14^{\text {th }}, 2013$ (the first day of the fifty-first session) was 49 . Approximately $80 \%$ of the Arizona State Senate and 55\% of the Arizona House of Representatives responded to this survey. Table 1 provides more details on the demographic statistics for the specific 
legislators that responded to this questionnaire. Roughly $70 \%$ of the respondents were male and 30\% were female. In addition, $63 \%$ were Republicans and 37\% were Democrats. The average respondent age was 50.24 years, and their average time in office was 5.63 years.

\section{INSERT TABLE 1 ABOUT HERE}

\section{Communication Technology Frequency of Use}

Age. To analyze the data for CT frequency of use by age, we conducted bivariate regression analyses on each CT as a function of age and education. Also, we compared the means (using t-tests) for CT frequency of use across different categories of gender, political party, and elected chamber. The results of these analyses are shown in Table 2 and Table 3. In order to determine a rank order of the CTs most frequently used by legislators, the nonlinear ratio level scales (a value of 0 for do not use, 1 for used annually, 2 for used monthly, and so on) were linearized into a number indicating the number of times the technology was used per year. In other words, a "use annually" response remained at a value of 1 (indicating a once per year use), a "use monthly" response was converted to a value of 12 (indicating a 12 times per year use), a "use weekly" response was converted to a value of 52, a "use daily" response was converted to a value of 365 , and a "use hourly" response was converted to a value of 3,285 (1 use per hour, times 9 hours per day, times 365 days per year).

\section{INSERT TABLE 2 ABOUT HERE}

\section{INSERT TABLE 3 ABOUT HERE}

To test hypotheses $\mathrm{H}_{1 a}, \mathrm{H}_{1 b}$, and $\mathrm{H}_{1 c}$, legislators were bifurcated into two age categories: younger (age $\leq 44.5^{3}$ years) and older (age $>$ mean age of 44.5 years) and 
assigned to a dummy variable older. Using difference of means testing as a function of the dummy variable older IECT communication events was greater for younger legislators than for older legislators (5935 and 3129 events per year, respectively; $p=0.030$ ), leading us to fail to reject hypothesis $\mathrm{H}_{1 \mathrm{a}}$. Interestingly, research by Sala \& Jones (2012) that broke legislators into age cohorts found age differences in social media use by Texas legislators yet no such differences in Mexican legislators in the state of Nuevo Leon. Sala \& Jones' results suggest that the relationship between legislator age and social media use may be (at least in part) a cultural phenomenon.

Next, we test hypothesis $\mathrm{H}_{1 \mathrm{~b}}$ (regarding legislator use of mature communications) using the same bifurcated age categories as Hypothesis $\mathrm{H}_{1 \mathrm{a}}$. The results of difference of means testing suggest that there are no statistically significant differences in how legislators use mature communications as a function of age $(p=0.065)$. These results lead us to reject hypothesis $\mathrm{H}_{1 \mathrm{~b}}$ and conclude that legislator use of mature CT does not vary significantly as a function of age.

As with the previous two hypothesis tests, examination of legislator social media use by bifurcated age categories suggests that younger legislators use social media 2464 times per year on average while older legislators use social media 672 times per year $(p=0.17)$ leading us to fail to reject hypothesis $\mathrm{H}_{1 \mathrm{c}}$. This result confirms Greenberg's (2012) study, we can conclude that social media use by legislators varies significantly with legislator age.

The results for $\mathrm{H}_{1 \mathrm{a}}, \mathrm{H}_{1 \mathrm{~b}}$, and $\mathrm{H}_{1 \mathrm{c}}$ are supported by scatter plots of the relationships showing 95\% confidence interval bands. Figure 1 shows the scatter plot between legislator 
age and IECT communications, for brevity, we do not show the scatter plots for hypotheses $\mathrm{H}_{1 \mathrm{~b}}$, and $\mathrm{H}_{1 \mathrm{c}}$.

In addition, we used multivariate OLS (for frequency related variables), ordinal nonlinear (for importance related variables), and confidence interval scatter plots to further explore our results. We conclude from these analyses that: 1) as shown in Figure 2, older and younger legislators communicate less often, 2) controlling for age, the longer a legislator has been in office, the less important they find face-to-face communications with constituents $(\mathrm{P}>|\mathrm{z}|=0.010)$, and 3$)$ controlling for years in office, the older a legislator is, the less important they find constituent communications $(\mathrm{P}>|\mathrm{z}|=0.029)$. These unexpected findings are discussed further in the following paragraphs.

\section{INSERT FIGURE 1 ABOUT HERE}

As discussed in our review of the literature, older individuals are expected to use Internet enabled CTs less frequently than their younger counterparts. In our research, total legislator communication is comprised of the sum of mature and IECT communications. It is reasonable therefore, to expect that overall communications should drop as a legislator ages unless an older legislator compensates by increasing their use of mature CT. In essence, as IECT communication frequency decreases as a function of age, overall communication frequency as we have defined it can be expected to decrease, all else equal.

Examination of the slope changes in the polynomial fit line and 95\% confidence interval shown in Figure 2 suggest that it would be prudent for us to categorize legislators in three age groups: 1) 35 or less years of age, 2) 35 to 60 years of age, and 3) over 60 years of age, and examine density functions for CT frequency of use. We find that legislator CT frequency of use is being influenced by at least two competing dynamics: younger 
legislators using mature CT less, older legislators using Internet enabled CT less, and legislators in the 35-60 age range using both IECT and mature CT more, creating a second order function peaking in the 35-60 year old range. This peaking can be seen in Figure 2 . Repeating the above CT frequency of use analyses for CT importance produces similar results: younger legislators find mature CT less important, older legislators find Internet enabled CT less important, and legislators in the 35-60 age find Internet enabled and mature CTs more important than their younger and older peers.

\section{INSERT FIGURE 2 ABOUT HERE}

Our second finding that even when controlling for age, the longer a legislator is in office, the less important they find face-to-face communications with constituents was surprising. Media richness theory suggests that CT can be selected to fit specific types of information in order to enhance understanding (Dennis, Valacich, Speier, \& Morris, 1998) and increase physiological arousal (Kock, 2005). Both media richness and media naturalness theory suggest that face-to-face communications are the richest and least ambiguous form of communication. Consistent with media richness and media naturalness theory, our study shows that face-to-face communications are the most important form of communications to legislators. So why do we find a negative correlation between face-toface communications with constituents and time in office? Also, why do we see no such decrease in the importance of face-to-face communications with other legislators?

While we could not find any existing research that directly addresses these questions, there are a few possible explanations for our findings. First, it is possible that our findings are the result of our relatively small sample size or non-probability sampling bias (i.e., a larger sample or probability study might not yield the same relationship). 
Second, our findings could reflect a decrease in motivation by older legislators. For example, the Herrick \& Thomas (2005) study on older state legislators suggests that they have less personal ambition than their younger peers. In our study, the correlation between legislator age and years in office is 0.53 (Spearman's rho, $p=0.00$ ), clearly linking years in office and age, and providing a possible correlation between our results and Herrick's. Reduced motivation could explain a reduction in the importance of communicating with constituents face-to-face as a function of years in office since these communications require much more time than other non face-to-face communications (Antoinette J. Pole, 2005; Wahlke, 1962). If, as Mayhew (2004) notes, "legislators are single-minded seekers of reelection" (p. 5), then it seems reasonable to expect that less ambitious legislators will communicate with their constituents less using the most timeconsuming format: face-to-face communications.

Of course, there are many other possibilities we do not have the space to fully explore here. To gain insight into these vast possibilities, a Google search of "legislators out of touch with constituents" produces 2,100,000 hits, many which hint that there may in fact be a growing communication gap between legislators and constituents and that our findings may reflect reality. A larger study would be useful to understand if the link we find between legislator CT frequency of use and age/years in office is reproducible. An exploratory mixed method approach may be most useful for disentangling the relationships between legislator age, years in office, and CT frequency of use and importance.

We conclude this section by examining the relationship between legislator use of IECTs and mature CTs as a function of age is an appropriate conclusion for this section. Our 
study suggests that there are numerous dynamics occurring: 1) younger legislators are increasing their use of IECT and decreasing their use of mature CTs as 2) older legislators are using IECT sparingly, and 3) legislators in the 35-60 year old range are using both IECT and mature CT more than their younger and older peers. These results would have been difficult to predict based on existing literature due to the lack of research comparing mature and IECT use by legislators. This finding is one of the most important findings in our study.

Legislator Gender. Multiple scholars have concluded that gender is not a significant predictor of CT use when a common IT infrastructure was shared (Akman \& Mishra, 2010; Knight \& Pearson, 2005; Thayer \& Ray, 2006). To test this second hypothesis, we conducted a series of bivariate regressions and t-tests for the frequency of use for each CT by gender for both constituent and peer communications. The results are reported in Table 2. In short, the relationships between frequency of use for each CT and gender were not statistically significant at the 0.05 level, leading to a failure to reject hypotheses $\mathrm{H}_{2 a}$ and $\mathrm{H}_{2 b}$. Based on the results shown in Tables 3 and 4, we can conclude that legislator gender was not correlated with CT use across all CTs. Several multivariate regression models were analyzed with respect to gender: 1) controlling for age and education, 2) controlling for chamber, years in office, and political party, and 3) controlling for age, education, chamber, years in office, and political party. Gender was not statistically significant in any of these models.

Legislator Education Levels. Drawing from the existing literature focused on nonlegislators (Chen \& Persson, 2002; Juznic et al., 2006; Tak \& Hong, 2005) we expected that legislator education levels would be significantly correlated with CT use. However, no such 
relationship was uncovered. The results of these analyses are reported in Tables 3 and 4 . Several multivariate regression models were analyzed with respect to education: 1) controlling for age and gender, 2) controlling for chamber, years in office, and political party, and 3) controlling for age, gender, chamber, years in office, and political party. None of these models were statistically significant. Our results are in contrast with research done by Williams \& Gulati (2009) who found a statistically significant (but small) difference between congressional legislators education and Facebook ${ }^{T M}$ use during campaigning. This difference may be related to our focus on legislators using CT for the purposes of performing their job as a legislator while Williams \& Gulati's research focused on Facebook $^{T M}$ use during campaigning. Supporting this perspective, Arizona legislators indicated that they used both Facebook ${ }^{T M}$ and Twitter ${ }^{T M}$ primarily for campaigning and not for the purposes of performing their duties as a legislator.

We also used a series of $t$ tests to compare the mean frequency of use variables for each CT across two education groups: less educated legislators (education $<16$ years) and more educated legislators (education $\geq 16$ years) ${ }^{4}$. The results were not statistically significant. Additionally, we ran bivariate regressions on each CT as a function of education. These results were not statistically significant either. Based on these analyses, we rejected hypotheses $\mathrm{H}_{3 a}$ and $\mathrm{H}_{3 \mathrm{~b}}$, and concluded that legislator education levels were not correlated with CT use (across all CTs). Legislator Political Party Affiliation. When focusing on the frequency of legislator communication with peers, we observed significant differences across political party for two CTs: email and telephone. As Table 2 illustrates, Democrats were significantly more likely than Republicans to use email and telephone when communicating with peers, while 
Table 3 suggests that Democrats were more likely to communicate with constituents via the telephone.

With respect to political party affiliation, we analyzed several multivariate regression models, including: 1) controlling for age and gender, 2) controlling for chamber, years in office, and political party, and 3) controlling for age, gender, chamber, years in office, and political party. The results of these multivariate regressions are summarized in Table 4. In model one, political party affiliation was statistically significant for telephone use with peers. In model two, political party affiliation was statistically significant for telephone and email use with peers, and in model three, political party affiliation was statistically significant for telephone. In all statistically significant multivariate regressions, Democrats were communicating more frequently than Republicans.

\section{INSERT TABLE 4 ABOUT HERE}

We conclude that legislators who are Democrats are more likely than Republicans to use both Internet enabled CTs and mature CTs. As discussed later in this paper, we suspect

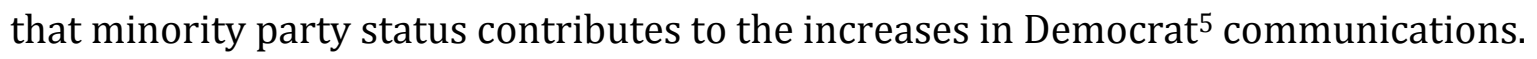
Consequently, we fail to reject hypotheses $\mathrm{H}_{4 a}$ and $\mathrm{H}_{4 \mathrm{~b}}$. These two hypotheses assumed that the minority political party (in this case, Democrats) would use both IECT and mature CTs more than the majority political party.

Legislator Chamber. Even though we expected legislator chamber to be correlated with frequency of use across CTs, our analyses did not support this hypothesis. Based on the results in Table 3, we can conclude that Arizona legislators did not display different frequency of use patterns as a function of chamber across all CTs, leading to a rejection of hypotheses $\mathrm{H}_{5 \mathrm{a}}$ and $\mathrm{H}_{5 b}$. With respect to chamber (House or Senate), we analyzed several 
multivariate regression models, including: 1) controlling for age and gender, 2) controlling for education, years in office, and political party, and 3) controlling for age, gender, political party, years in office, and education. We did not uncover any statistically significant relationships in these analyses. However, there is one important note related to these results. This note is that the state of Arizona has term limits. In other words, State Legislators in Arizona that "term out" (West, 2014, p. 74) in one chamber frequently move back and forth between chambers to stay in office and avoid the two year waiting period before being allowed to return to the same chamber necessitated by Arizona law. In effect, differences in legislator behavior could be homogenized by legislators moving back and forth between chambers in an effort to avoid term limits.

Legislator Frequency of CT use with Peers and Constituents. Frequency of use questions were presented in a binary use per unit time format (use annually, use monthly, and so on) to simplify response and increase response rates. It is reasonable to ask why, if we were interested in determining how many times a legislator used a CT in a year, we did not simply ask that question on the survey. Surveys of elite populations (including state legislators) are often plagued with low response rates (Maestas, Neeley, \& Richardson, 2003) which can be increased by simplifying questions. In order to increase response rates, we simplified the response categories for these questions.

As discussed at the beginning of this section on CT frequency of use, this approach of using post-hoc processing of simple question Likert "appearing" scales that are actually ratio level scales is supported in Carifio et al.'s (2007) paper "Ten Common Misunderstandings, Misconceptions, Persistent Myths and Urban Legends about Likert Scales and Likert Response Formats and their Antidotes". In debunking myth number 6 (i.e., 
"because Likert scales are ordinal-level scales, only non-parametric statistical tests should be used with them") (p. 114), Carifio and colleagues note that Likert response formats may also be ratio-level scales if the correct anchoring terms are used. Ratio-level anchoring terms consist of a zero value that means zero of the quantity being measured (in this case, zero represents that the legislator does not use the $\mathrm{CT}$ ) and maximum and intermediate values that maintain ratio-level relationships. Our data meet both of these requirements. We recognize that such post-hoc calculations are not universally accepted and therefore the results for both the original Likert response scale and the linearized scale are reported in Table 5.

Using E-Mail in Table 5 as an example, in the first column we see that E-Mail is ranked first when communicating with constituents both from the perspective of the linearized scale and (in parentheses) the raw Likert scale ranking. In the second column for E-Mail, we report the linearized average number of constituent E-Mail communication events (1,504 E-Mails) and the nonlinear Likert scale score of 4.16 (indicating constituent E-Mails occur somewhere between daily use (Likert scale $=4$ ) and hourly use (Likert scale $=5$ ). Columns three and four are a repeat of columns two and three using peer communications instead of constituent communications. In column five, the linearized and nonlinear Likert ranking is shown for the sum of constituent and peer communications using E-Mail.

Using post-hoc calculations to weight the frequency of use responses allowed the mean weighted score for each CT to be used as an indicator of relative frequency of use, with the higher mean scores indicating higher frequency of use. The linearized numbers shown in Table 5 represent an estimate of the mean number of uses per year for each CT. 
The actual conversion factor (times per year, per month, per week, and so on) used is not of concern, as long as it is applied consistently and logically across all ordinal categories. In effect, the conversion factor changes the slope of all coefficients evenly if applied consistently, and does not change the relationships between the coefficients themselves. Put another way, if all the slopes of the linearized variables change the same, the relationship between the various slopes remains unchanged.

\section{INSERT TABLE 5 ABOUT HERE}

The results listed in Table 5 suggest that legislators used E-mail most frequently to communicate with constituents and other legislators. Unsurprisingly, legislators communicated more frequently with each other via face-to-face meetings and telephone than they did with their constituents. On the other hand, legislators communicated more frequently with constituents using Twitter ${ }^{\mathrm{TM}}$ and Facebook ${ }^{\mathrm{TM}}$, while the frequency of use of hardcopy letters, web pages, and blogs were similar for communications with peer legislators and constituents.

A comparison of the raw frequency of use mean scores and the linearized scores shown in Table 5 suggest that linearizing these data do not significantly change the nature of the results for most CTs. For example, examination of the linearized and raw overall frequency of use ranking in column 5 shows that E-Mail was the most frequently used CT, followed by face-to-face communications and the telephone ranked which are only slightly different in raw and linearized frequency of use. As shown in Table 5, Facebook ${ }^{\mathrm{TM}}$ is ranked fourth in both raw and linearized form, as is webpage use (ranked $6^{\text {th }}$ overall) and blog use (ranked $8^{\text {th }}$ overall). Twitter ${ }^{\text {TM }}$ (ranked $5^{\text {th }}$ in linearized form and $7^{\text {th }}$ in raw form) and letter use (ranked $7^{\text {th }}$ in linearized form and $5^{\text {th }}$ in raw form) offer the greatest differences 
between raw and linearized rankings. These results suggest that linearizing these data had a minimal impact on the overall CT frequency of use rankings.

Since legislators provided information on how frequently they communicate with peers and constituents, we were able to calculate an overall communication score as the sum of peer and constituent communications for each legislator. Once calculated, we examined this overall communication score for relationships with demographic and institutional variables. In particular, we ran several multivariate regression models using overall communication frequency as our dependent variable and controlling for: 1) age and gender, 2) education, years in office, chamber, and political party, and 3) age, gender, chamber, years in office, political party, and education. The results of all three multivariate regressions are summarized in Table 4. Overall frequency of communication was statistically significant in its relationship with age in model one $(p=.050, r$-squared $=9.8 \%)$ and with years in office in model two $(p=.032$, $r$-squared $=17.1 \%)$. In model one, a oneyear increase in time in office results in a 192-instance reduction in communication events per year, all else equal. In model two, a one-year increase in years in office results in a 489instance reduction in communication events per year.

Recognizing that it may be difficult to keep track of 11 hypotheses, we have summarized the results of our hypotheses testing in Table 6. As shown in Table 6, a number of our hypotheses did not produce the results suggested by our literature review and were rejected. The rejected CT frequency of use hypotheses include the hypotheses associated with education and those associated with legislator chamber. A brief discussion of these rejected hypotheses follows.

INSERT TABLE 6 ABOUT HERE 
Based on our literature review, we expected legislator education to be correlated with legislator use of CT. Specifically, we hypothesized that more educated legislators would communicate more via IECT and mature communications. Our analyses showed no such correlations. Importantly, all of the research we based our education hypotheses on with the exception of Williams \& Gulati (2009) were focused on non-legislators, which may account for our unexpected results. In addition, Williams \& Gulati's work had a much larger sample size allowing them to detect smaller effect sizes. A thorough examination of their study shows that the effects of legislator education on Facebook ${ }^{\mathrm{TM}}$ use were very small. In effect, a larger sample size would have decreased our effect size, potentially allowing us to replicate the results found by Williams \& Gulati.

Our second and final pair of rejected CT frequency of use hypotheses were related to elected institution (chamber). Based on existing research, we expected to see differences in how legislators communicate as a function of institution. The literature we used to develop these hypotheses did not report inferential statistics, but rather, reported descriptive statistics. Our examination of the descriptive statistics in our dataset for Facebook ${ }^{\mathrm{TM}}$ and Twitter $^{\mathrm{TM}}$ use showed that Senators used Twitter ${ }^{\mathrm{TM}}$ more than Representatives (the same result that Greenberg (2012) found with U.S. Senators), but Representatives used Facebook $^{\mathrm{TM}}$ more than Senators (a finding different than Greenberg's, who was investigating U.S. Senators and not state Senators as we were). Similarly, we found that Arizona Representatives use E-Mail more than Senators, a finding that mirrors Alperin's (2003) results. In effect, in two out of the three cases, our results mirror work done by other scholars if we use descriptive statistics as they did. Once we examine these data using inferential statistics, however, the results are not statistically significant. The lack of 
statistical significance may be related to the low power/large effect size precipitated by our sample size.

\section{Importance of Communication Technologies}

In addition to determining how frequently legislators used specific CTs to communicate with their constituents and peers, our survey results allow us to measure the overall importance that legislators associate with CTs when they are used to communicate with constituents and peers (from 1=Not Important to 5=Very Important, with $0=$ Do Not Use). Table 7 summarizes the importance legislators assigned to each CT for both peers and constituents.

\section{INSERT TABLE 7 ABOUT HERE}

The results shown in the first four columns of Table 7 suggest that the relative importance ranking of the various CTs are the same for peers and constituents. This is not to say, however, that the importance of each CT when used to communicate with peers and constituents is the same. For example, face-to-face meetings with constituents have an average mean score of 4.79 (between important and very important) while the average mean score of face-to-face meetings with other legislators is 3.98. For all CTs, the mean score for the importance when communicating with constituents is higher than the mean score when communicating with other legislators. Column 4 in Table 7 shows that the differences in mean importance scores between constituents and peers are all statistically significant. In other words, for all CTs, legislators placed more importance on communicating with constituents than on communicating with peers. One possible explanation for the increased importance legislators assign to constituent communications is offered by Mayhew (2004) who famously argues that legislators are "single-minded 
seekers of reelection" (p. 5). If legislators are continually focused on reelection, then the increase in importance they assign to constituent communications over peer communications may reflect a tacit understanding that constituents are directly responsible for their reelection. And finally, column 5 of Table 7 shows the overall importance (peer plus constituent) ranking of each CT.

E-Mail was the most frequently used CT for both peers and constituents. Furthermore, the important of email (according to legislator interviews conducted as part of this research ${ }^{6}$ ) was related to legislator time constraints and the mass publication capability of E-Mail. In our follow-up interviews, legislators stated that E-Mail allows them the opportunity to deal with routine issues and address large numbers of constituents quickly. Importantly, legislators indicated that E-Mail is useful for sending information to constituents while at the same time indicating that E-Mail from constituents is of lower importance than phone calls and face-to-face communications. These results support and extend Greenberg's (2012) contention that legislators use social media more "as a megaphone, rather than a discussion tool for interacting with individuals" (p. 18).

Ordinal logistic regressions were completed on the importance of each CT and the demographic variables age, gender, education, political party, and chamber, for both peer and constituent communications. The results of these bivariate regressions are shown in Table 8.

\section{INSERT TABLE 8 ABOUT HERE}

Although no hypotheses were formed on the importance of CTs to legislators, the results shown in Table 8 suggest that there are some statistically significant relationships. Perhaps unsurprisingly, age appears to play a dominant role. The odds of finding face-to- 
face meetings with constituents, peer communications using Facebook ${ }^{\mathrm{TM}}$ and Twitter $^{\mathrm{TM}}$, constituent communications via web pages and Twitter ${ }^{\mathrm{TM}}$ important all decrease as a function of increasing age. Out of all of these relationships, the most interesting is the decrease in the importance of face-to-face communications as legislators age, a finding that will be discussed further in the next paragraph and which will be the focus of an upcoming research project covering legislators in all states. In addition, we found that Senators were 80\% less likely ( $\mathrm{p}=.032$ ) than Representatives to view face-to-face communications with constituents as important. Also, Senators were 79\% less likely than Representatives $(p=.004)$ to view communications with constituents via web pages as important.

As we noted in our previous paragraph, one of the more interesting relationships uncovered by our research is our finding that older legislators in our study find decreasing importance in face-to-face communications. Examination of Table 8 suggests that age plays a significant role in the decrease in importance of not only face-to-face meetings with constituents, but decreases in the importance of IECT communications with peers. Decreases in the importance of IECT communications were expected based on existing literature already discussed. Our finding that the decrease in the importance of face-to-face communications such that a one year increase in a legislator's age is correlated with a seven percent decrease in the odds that a legislator will find face-to-face meetings with constituents "Very Important" compared to all other level of importance choices in our survey. We explore this finding further in following paragraphs.

One reasonable question that can be asked is whether the decrease in the importance of face-to-face meetings with constituents as a function of age is associated with a decrease in the frequency of use of face-to-face meetings with constituents. Ordinal 
logistic regressions suggest that there is a $3 \%$ reduction in the odds that a legislator will select "Use Daily" for the frequency of use of face-to-face communications with constituents as a function of age $(p=0.14)$, but our sample size limits statistical power such that this relationship is not statistically significant at the $95 \%$ confidence interval. This result, although not statistically significant, leans in the expected direction and suggests that our findings are likely to be sound. A follow-on study with a larger sample size (all state legislators in the United States) is already planned. We discuss the implications of this finding further at the conclusion of this paper.

\section{The Relationship Between Frequency of Use and Importance}

We expected that there would be a positive correlation between CT frequency of use and CT importance. Bivariate regression analyses exploring the relationships between CT importance and CT frequency of use confirm these relationships. Table 4 contains the results of three robust regression models. Model one contains the overall CT frequency of use (peer + constituent for all CTs) and overall importance (peer + constituent for all CTs). Model two adds demographic controls for gender, age, and education to model one. Model three adds controls for political party, elected chamber, and years in office to model two. Multicollinearity did not appear to be a problem in any of the three models because Variance Inflation Factors (VIFs) were under the commonly accepted threshold of 10 (Mela \& Kopalle, 2002; Schroeder, Lander, \& Levine-Silverman, 1990). Furthermore, condition indices, considered to be one of the best methods to detect multicollinearity issues in a multivariate regression model (Saperstein, 2010) were under the threshold of 30, indicting inconsequential multicollinearity (Mela \& Kopalle, 2002). 
While we expected correlation between CT frequency of use and CT importance, we cannot rule out the fact that this relationship may be caused by common source variance. As discussed by Antonakis et al. (Antonakis, Bendahan, Jacquart, \& Lalive, 2010), common source variance occurs when a common source (in this case, a legislator taking the survey) "strives to maintain consistency between the two types of ratings" (p. 1096). In this specific case, a legislator responding to our question regarding CT frequency of use may have attempted to maintain consistency in her/his responses by assigning a higher importance to the CTs they use most frequently. Although we mention common source variance with respect to the relationship between CT frequency of use and CT importance, common source variance could occur between any of our independent variables.

The results of Table 4 suggest that the relationship between CT frequency of use and importance is statistically significant for all models, even after controlling for demographic, institutional and political variables. Using the full model as an example, the results can be read as a one-unit increase in the importance of CT is correlated with a 313-instance increase in the frequency of use of a CT, all else equal. Interestingly, the being a Republican is associated with a decrease in the frequency of use of CT by 5351 occurrences per year, all else equal.

Technology Hardware Use. Legislator use of technology hardware (electronic devices) was indicated by a single composite variable techuse, which varied from a value of zero (indicating that a legislator never used any of the technology hardware listed) to a value of 26,280 (indicating that a legislator used all of the technology hardware listed every hour in a 9 hour legislative day, 365 days per year) ${ }^{7}$. Legislators were asked how frequently they used the following hardware devices: desktop computer, laptop computer, net-book 
computer, tablet device, smart phone, basic cell phone, smart watch, and pocket digital media player.

To determine statistically significant relationships between hardware technology use and demographic characteristics, we ran a series of bivariate regression models with hardware technology use as the dependent variable and party identification, gender, chamber, age, education, years in office, and mail mode response as independent variables. Only the relationship between hardware technology and number of years in office was statistically significant. The results indicated that a 1-year increase in the number of years a legislator has been in office is correlated with a 213-unit decrease in hardware technology use score, on average, all else equal. Bivariate regressions were also completed with hardware technology use as the IV and all CTs as the DV, for both peer and constituent communications. Table 9 outlines the statistically significant results of these bivariate regressions.

\section{INSERT TABLE 9 ABOUT HERE}

Using constituent E-mail communications as an example, the results can be interpreted as a 10-time per year increase in the use of hardware technology was correlated with an increased use of E-mail by 1.97 times per year.

\section{Conclusion}

Our goals in this article are focused on exploring how Arizona State Legislators use CTs in their work life - and to learn more about the level of importance that they place on different CTs. In this section, we draw on our results to offer some important take-home messages from our research study. First, from a practical perspective, constituents would be wise to communicate with their legislators using face-to-face communications or the 
telephone because legislators place more importance on these forms of communication from constituents. In face-to-face interviews with legislators (West, 2014), every legislator interviewed indicated that personal communications from constituents are preferred to impersonal communications. For example, legislators prefer to meet with their constituents face-to-face or over the phone, and find personal E-Mail from a constituent to be more important than "boilerplate" E-Mails that are copied and pasted from external sources.

Second, our results indicate that constituents might be more effective in communicating with younger legislators via Internet enabled communications technologies - and they might be more effective using mature CTs with more senior legislators. This is because our analyses demonstrated that younger legislators are more likely to use these technologies than older legislators. These results also have implications for how the next generation of legislators will choose to communicate with each other and their constituents.

Third, our study has demonstrated that age related variations in the use of the CTs examined are likely to cease to be a factor within one or two generations. In other words, as older legislators who are resistant to the use of "newer" CTs retire, younger generations of legislators who have been exposed to these technologies are unlikely to exhibit variations in the use of these technologies as a function of age.

Our research has significant implications for researchers. First, we have shown that legislator use of CT is extremely complex. For example, we have shown that younger legislators are using Internet enabled CT more frequently than older legislators but are using mature CTs less frequently. Older legislators are using both Internet enabled CT less frequently than their younger counterparts, and middle-aged legislators are 
communicating more than both younger and older legislators as they balance the use of both Internet enabled CT and mature CT.

With Internet enabled CTs such as Facebook ${ }^{\mathrm{TM}}$, Twitter ${ }^{\mathrm{TM}}$, and YouTube ${ }^{\mathrm{TM}}$ dominating research into legislator communications, our research suggests that a theoretical focus on all forms of CT, including mature CT such as face-to-face meetings is important. The dearth of research examining the relationships between evolutionarily mature communications such as face-to-face interactions and new forms of communication technology such as Facebook $^{\mathrm{TM}}$ or Twitter ${ }^{\mathrm{TM}}$ seem to imply that mature communications are not important from a research perspective. Simply put, our research clearly shows that legislators find mature CTs more important, yet a review of the literature highlights researcher focus on IECT. Specifically; as researchers focus on how IECT is changing the political landscape, legislator use of mature communications are changing too; and not in ways that may be expected. In fact, the dynamic relationship between the use and importance of mature and IECT communications may help explain disconnects between legislators and constituents currently being discussed in the popular press.

The communication disconnects between legislators and constituents can be clearly seen by our research. For example, as shown in Table 7, legislators find face-to-face communications most important when communicating with constituents, but we know from research (West, 2014) that constituents ${ }^{8}$ are communicating with legislators most frequently via E-Mail. Importantly, we have shown some of the dynamics that exist between mature and Internet enabled CTs, dynamics that suggest that CT frequency of use and Importance are significantly different between younger, middle-aged, and older 
legislators. There is no "one size fits all" when it comes to the best way for a constituent to communicate with a legislator.

In addition to providing practical value for constituents and theoretical implications for researchers, our research offers important lessons for legislators as well. Older legislators and legislators who have been in office would be well served to note the trend of decreased communications as a function of age and years in office. Although we have offered some theoretical explanations for these phenomena, legislators remain largely in control of their communication habits (notwithstanding the requirements of staff such as communication directors), and can make adjustments based on the relationships uncovered by our research.

As is typical with exploratory studies, this study leaves many questions to be answered by future studies. These questions include: Does the use of CT impact a legislator's policy decisions? What variables drive the importance a legislator assigns to a CT? Is there a link between a legislator's choice of communication method and the ideology of the political party they belong to? Can the differences between majority and minority party communication frequency be found in other state legislatures, and if so, what are the drivers for these differences? Is there a relationship between the Burkean roles of delegate, trustee, and politico and the frequency of use and importance a legislator assigns to a particular CT? For example, does reduced constituent communication frequency indicate that a legislator is more of a trustee than a delegate? Does the reduced importance of communication with constituents as a legislator ages suggest that Burkean roles shift as a function of legislator age? We hope that the insights offered in this paper spur future 
research that places renewed focus not only on what legislators communicate, but how they choose to communicate it. 


\section{References}

Akman, I., \& Mishra, A. (2010). Gender, age and income differences in internet usage among employees in organizations. Computers in Human Behavior, 26(3), 482-490.

Alperin, D., \& Schultz, D. (2003). E-Democracy: Legislative-constituent communications in Minnesota and Wisconsin.

Antonakis, J., Bendahan, S., Jacquart, P., \& Lalive, R. (2010). On making causal claims: A review and recommendations. The Leadership Quarterly, 21(6), 1086-1120.

Carifio, J., \& Perla, R. J. (2007). Ten common misunderstandings, misconceptions, persistent myths and urban legends about Likert scales and Likert response formats and their antidotes. Journal of Social Sciences, 3(3), 106.

Carpenter, B. D., \& Buday, S. (2007). Computer use among older adults in a naturally occurring retirement community. Computers in Human Behavior, 23(6), 3012-3024.

Chen, Y., \& Persson, A. (2002). Internet use among young and older adults: Relation to psychological well-being. Educational Gerontology, 28(9), 731-744.

Cody, M. J., Dunn, D., Hoppin, S., \& Wendt, P. (1999). Silver surfers: Training and evaluating Internet use among older adult learners. Communication education, 48(4), 269-286.

Conte, C. (1999). Laptop legislatures. Governing, 13(2), 36-44.

Cook, T. E. (1989). Making laws and making news: Media strategies in the US House of Representatives: Brookings Institution Press.

Cooper, C. A. (2002). Media and the state legislature: How state legislators use media tactics to achieve legislative goals. (3054103 Ph.D.), The University of Tennessee, United States -- Tennessee. ProQuest Dissertations \& Theses Full Text database.

Cooper, C. A. (2004). Internet Use in the State Legislature A Research Note. Social science computer review, 22(3), 347-354.

Cutler, S. J., Hendricks, J., \& Guyer, A. (2003). Age differences in home computer availability and use. The Journals of Gerontology Series B: Psychological Sciences and Social Sciences, 58(5), S271-S280.

Dahl, R. A. (1989). Democracy and its Critics: Yale University Press.

Dennis, A. R., Valacich, J. S., Speier, C., \& Morris, M. G. (1998). Beyond media richness: An empirical test of media synchronicity theory.

Dillman, D. A., Smyth, J. D., \& Christian, L. M. (2009). Internet, Mail, and Mixed-Mode Surveys: The Tailored Design Method (Third ed.): John Wiley \& Sons Inc. 
Fang, X., \& Yen, D. C. (2006). Demographics and behavior of Internet users in China. Technology in Society, 28(3), 363-387.

Friedberg, L. (2001). The impact of technological change on older workers: Evidence from data on computer use. Retrieved from

Graham, S. (2002). Bridging urban digital divides? Urban polarisation and information and communications technologies (ICTs). Urban Studies, 39(1), 33-56.

Green, D. P., \& Gerber, A. S. (2004). Get out the vote. How to increase voter turnout. Washington (DC): The Brookings Institution.

Greenberg, S. R. (2012). Congress and Social Media. Retrieved from Center for Politics and Governance:

Herrick, R., \& Thomas, S. (2005). Do term limits make a difference? Ambition and motivations among US state legislators. American Politics Research, 33(5), 726-747. doi:10.1177/1532673x04270935

Hills, P., \& Argyle, M. (2003). Uses of the Internet and their relationships with individual differences in personality. Computers in Human Behavior, 19(1), 59-70.

Hogan, M. (2006). Technophobia amongst older adults in Ireland.

Inouye, B. (2014). Communication Strategy in the 1976 Presidential Campaign.

Juznic, P., Blazic, M., Mercun, T., Plestenjak, B., \& Majcenovic, D. (2006). Who says that old dogs cannot learn new tricks?: A survey of internet/web usage among seniors. New Library World, 107(7/8), 332-345.

Kedrowski, K. M. (1992). Media entrepreneurs and the media enterprise in the United States Congress: Influencing policy in the Washington community. (9311014 Ph.D.), The University of Oklahoma, Ann Arbor. ProQuest Dissertations \& Theses Full Text database.

Knight, M. B., \& Pearson, J. M. (2005). The changing demographics: The diminishing role of age and gender in computer usage. Journal of Organizational and End User Computing (JOEUC), 17(4), 49-65.

Kock, N. (2005). Media richness or media naturalness? The evolution of our biological communication apparatus and its influence on our behavior toward ecommunication tools. Professional Communication, IEEE Transactions on, 48(2), 117130.

L, K., Morrell, R. W., Park, D. C., Christopher, B., \& Mayhorn, C. (1999). Predictors of electronic bulletin board system use in older adults. Educational Gerontology, 25(1), 19-35. 
Lassen, D. S., \& Brown, A. R. (2011). Twitter The Electoral Connection? Social science computer review, 29(4), 419-436.

Lathrop, D., \& Ruma, L. (2010). Open Government: Collaboration, Transparency, and Participation in Practice: Oreilly \& Associates Inc.

Li, N., \& Kirkup, G. (2007). Gender and cultural differences in Internet use: A study of China and the UK. Computers \& Education, 48(2), 301-317.

Madden, G., \& Savage, S. J. (2000). Some economic and social aspects of residential Internet use in Australia. The Journal of Media Economics, 13(3), 171-185.

Maestas, C., Neeley, G. W., \& Richardson, L. E. (2003). The state of surveying legislators: Dilemmas and suggestions. State Politics \& Policy Quarterly, 3(1), 90-108.

Mayhew, D. R. (2004). Congress: The electoral connection (Vol. 26): Yale Univ Pr.

Mela, C. F., \& Kopalle, P. K. (2002). The impact of collinearity on regression analysis: the asymmetric effect of negative and positive correlations. Applied Economics, 34(6), 667-677.

Mergel, I. (2012). Social Media in the Public Sector: A Guide to Participation, Collaboration and Transparency in The Networked World: Jossey-Bass.

Messmer, J. P. (2001). The rise of the cyber-legislator: Congress and the Internet in the latetwentieth century. (3013003 Ph.D.), University of Missouri - Columbia, United States -- Missouri. ProQuest Dissertations \& Theses Full Text database.

Morris, A., Goodman, J., \& Brading, H. (2007). Internet use and non-use: views of older users. Universal Access in the Information Society, 6(1), 43-57.

Morris, M. G., Venkatesh, V., \& Ackerman, P. L. (2005). Gender and age differences in employee decisions about new technology: An extension to the theory of planned behavior. Engineering Management, IEEE Transactions on, 52(1), 69-84.

Oleszek, W. J. (2011). Congressional procedures and the policy process (Eighth ed.): CQ press.

Peacock, S. E., \& Künemund, H. (2007). Senior citizens and Internet technology. European journal of ageing, 4(4), 191-200.

Peterson, R. D. (2012). To tweet or not to tweet: Exploring the determinants of early adoption Of Twitter by House members in the 111th Congress. Social Science Journal, 49(4), 430-438. doi:10.1016/j.soscij.2012.07.002

Pole, A. J. (2000). The role of computing technology and the New York state legislature. PUBLIC ADMINISTRATION AND PUBLIC POLICY, 77, 299-314. 
Pole, A. J. (2005). E-Mocracy: Information Technology and the Vermont and New York State Legislatures. State \& Local Government Review, 37(1), 7-24. doi:10.2307/4355383

Pratt, M., Sarmiento, O. L., Montes, F., Ogilvie, D., Marcus, B. H., Perez, L. G., \& Brownson, R. C. (2012). The implications of megatrends in information and communication technology and transportation for changes in global physical activity. The Lancet.

Sala, J. F. A., \& Jones, M. P. (2012). The Use of Electronic Technology and Legislative Representation in the Mexican and US States: Nuevo Le $\sqrt{ } \geq \mathrm{n}$ and Texas.

Saperstein, S. L. (2010). Factors related to listeriosis prevention in pregnant women: A mixed methods exploratory study. (3409726 Ph.D.), University of Maryland, College Park, Ann Arbor. ProQuest Dissertations \& Theses Full Text database.

Schroeder, M. A., Lander, J., \& Levine-Silverman, S. (1990). Diagnosing and dealing with multicollinearity. Western journal of nursing research, 12(2), 175-187.

Selwyn, N., Gorard, S., Furlong, J., \& Madden, L. (2003). Older adults' use of information and communications technology in everyday life. Ageing and Society, 23, 561-582. doi:10.1017/s0144686x03001302

Straus, J. R., Glassman, M. E., Shogan, C. J., \& Smelcer, S. N. (2013). Communicating in 140 Characters or Less: Congressional Adoption of Twitter in the 111th Congress. PS: Political Science \& Politics, 46(01), 60-66.

Tak, S. H., \& Hong, S. H. (2005). Use of the Internet for health information by older adults with arthritis. Orthopaedic Nursing, 24(2), 134-138.

Thayer, S. E., \& Ray, S. (2006). Online communication preferences across age, gender, and duration of Internet use. CyberPsychology \& Behavior, 9(4), 432-440.

Wahlke, J. C. (1962). The legislative system: Explorations in legislative behavior: Wiley.

Warschauer, M. (2004). Technology and social inclusion: Rethinking the digital divide: the MIT Press.

West, J. F. (2014). rEvolutionary Changes: The Complex Relationships Between Legislators and Communication Technology. (Ph.D.), Arizona State University, Ann Arbor. ProQuest Dissertations \& Theses Full Text database.

Williams, C. B., \& Gulati, G. J. (2009). Facebook grows up: An empirical assessment of its role in the 2008 congressional elections. Proceedings from Midwest Political Science Association, Chicago. 
Table 1 Legislator Demographics

\begin{tabular}{|c|c|c|}
\hline Demographic Variable & $\begin{array}{c}\text { Number of } \\
\text { Responses }\end{array}$ & $\begin{array}{c}\text { Summary Statistics } \\
\text { (For our Study Sample) }\end{array}$ \\
\hline $\begin{array}{c}\text { AZ State House of Representatives } \\
\text { (Democrats and Republicans) }\end{array}$ & 32 & $53 \%$ of the House \\
\hline $\begin{array}{c}\text { AZ State Senate } \\
\text { (Democrats and Republicans) }\end{array}$ & 24 & $80 \%$ of the Senate \\
\hline Democrat & 21 & $\begin{array}{c}55 \% \text { of Democrats in both } \\
\text { House and Senate }\end{array}$ \\
\hline Republican & 35 & $\begin{array}{c}67 \% \text { of Republicans in both } \\
\text { House and Senate }\end{array}$ \\
\hline Male & 37 & $\begin{array}{c}65 \% \text { of Male Legislators in } \\
\text { both House and Senate }\end{array}$ \\
\hline Female & 16 & $\begin{array}{c}49 \% \text { of Female Legislators } \\
\text { in both House and Senate }\end{array}$ \\
\hline Years In Office & 55 & $\begin{array}{c}\text { Mean }=5.63 \\
\text { Std. Dev. } 5.17\end{array}$ \\
\hline Age & 54 & $\begin{array}{c}\text { Mean }=50.24 \\
\text { Std. Dev. }=13.64\end{array}$ \\
\hline Education & 54 & $\begin{array}{c}\text { Mean }=17.44^{9} \\
\text { Std. Dev. }=3.16\end{array}$ \\
\hline
\end{tabular}

